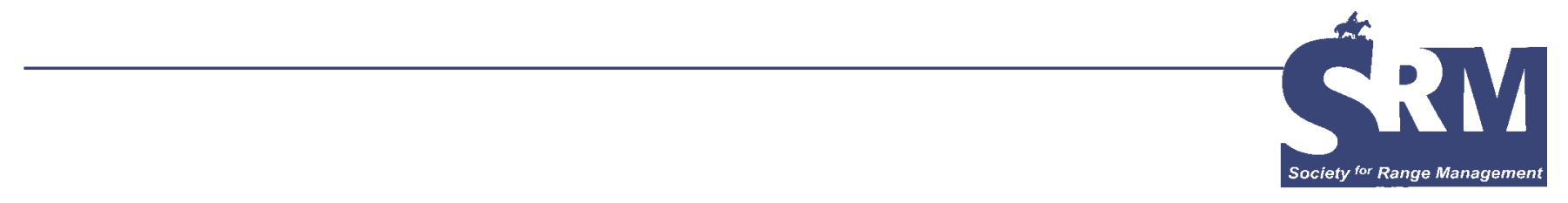

\title{
Semi-Arid Rangelands and Carbon Offset Markets: A Look at the Economic Prospects
}

\section{Potentially new economic opportunities for rangeland managers}

\section{By J. E. de Steiguer}

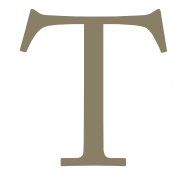

here has been an increasing interest in rangelands in recent years for their carbon storage potential to help reduce the atmospheric greenhouse effect. ${ }^{1}$ Although terrestrial carbon-storage projects will never be a permanent solution to global warming, they may be the bridge to a long-term solution for greenhouse gas emissions. Furthermore, through the sale of carbon credits, carbon-storage projects could provide cash flows to assist rangeland managers while also helping the environment. For example, one recent study looked at the economic possibilities for carbon storage on private grazing lands in the United States and concluded that it was a "win-win opportunity."

The purpose of this article is to examine the economic prospects for semiarid rangeland participation in carbon offset markets. To that end, it explores the results of a recent study of carbon sequestration on Arizona's rangelands and considers their possibilities in carbon-offset trading. In order to provide a context for this topic, let us first begin with a look at the Kyoto Protocol, the principal international global change policy, and then examine regional emissions trading and carbon offsets.

\section{Kyoto Protocol}

In 1997, the Kyoto Protocol emerged as the principal international policy to seek reductions in greenhouse gases (GHGs). Under the Kyoto Protocol, many of the world's industrialized nations have agreed to reduce their GHG emissions, which are largely carbon dioxide, by about 5\% over 1990 levels during the period 2008-2012. The developing countries of the world, including the emerging economic giants China and India, are not bound to these same reductions. The Kyoto Protocol was brought into force in February 2005 and has since been ratified by 169 nations.

The Kyoto Protocol provides market-based approaches to achieve carbon dioxide emission reductions (Fig. 1). Under one such arrangement, called "cap-and-trade," a nation sets an upper limit, or "cap" expressed in tons per year, upon national carbon dioxide emissions. That total cap is then parceled out in the form of pollution permits issued to individual polluting companies, such as power plants, oil refiners, cement manufacturers, pulp and paper producers, and the like. If a company's annual emissions fall below its permissible level, then it has excess pollution allowances to sell. If, on the other hand, a company exceeds its permissible pollution allowance it can either clean-up the excess pollution through technological improvements or purchase sufficient allowances from another party to cover the deficit. The attraction of cap-and-trade is that it allows companies to choose the least costly way of achieving their pollution targets. An example of this economizing potential can be found in the United States' sulphur dioxide cap-and-trade program mandated by Title IV of the Clean Air Act Amendments of 1990, which has proven in practice to be more cost effective than direct regulation. ${ }^{3}$

The European Union Emission Trading Scheme, involving two dozen nations, is the world's most extensive Kyoto-derived cap-and-trade trade arrangement. ${ }^{4}$ Under this scheme, each country sets its carbon dioxide cap based 
Market-based measures are increasingly being used to help mitigate emissions of greenhouse gases such as carbon dioxide. With cap-and-trade mitigation measures, a regional limit is set on total emissions and each polluting company is assigned a portion of the cap as their permissible annual emission allowance.

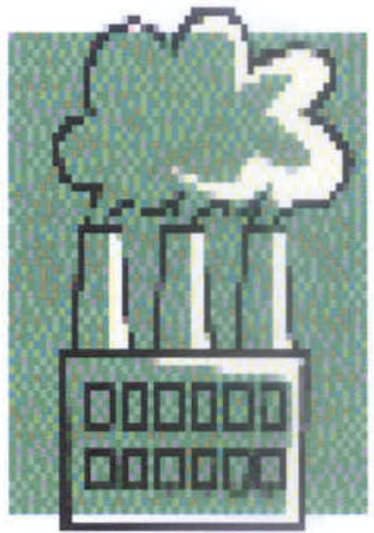

If Company $\mathrm{A}$ emits less than its allowance, it can sell unused emission allowances to companies that have exceeded their assigned limits.
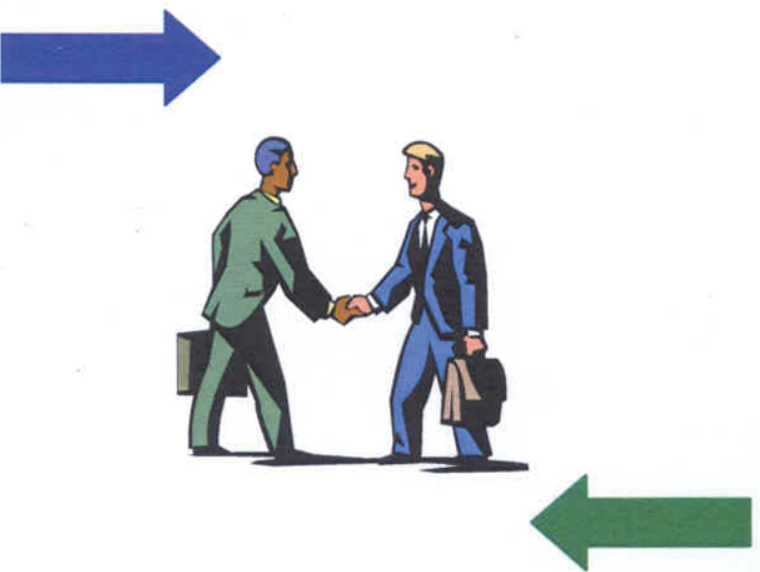

If Company B's emissions exceed its allowance, it can buy

emission allowances from companies that are under

their permissible levels.

With carbon offsets mitigation, Company B might also cover excess

emissions by purchasing credits from a carbon storage project, such

as one for rangeland grazing improvement.

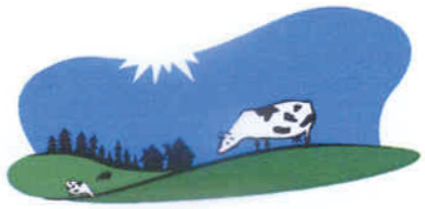

Supporters claim that market-based mitigation makes sense both ecologically and economically by achieving environmental goals at the least possible cost.

Adapted from Allianz Knowledge:

Figure 1. Market-based mitigation. 
upon Kyoto Protocol requirements and then allocates that cap among GHG-emitting entities. All annual emission levels are reported to and verified by the national government, by the European Union and by the United Nations. Emission allowance trading is accomplished companyto-company or through commercial carbon exchanges, which operate like stock brokerages bringing together allowance buyers and sellers. Currently, the EU Scheme recognizes nine exchanges operating in the United States, Austria, Holland, Germany, Canada, Norway, France, and Spain.

In addition to the EU Trading Scheme, there are numerous regional cap-and-trade efforts around the globe not directly related to the Kyoto Protocol. The most ambitious US-based effort is the Regional Greenhouse Gas Inventory, a cap-and-trade system supported by eight New England and Mid-Atlantic states. Also, Arizona, California, New Mexico, Oregon, and Washington, through the Western Regional Climate Action Initiative, have recently announced their intent to develop a regional target for reducing GHGs with a cap-and-trade program. Thus, interest in carbon emissions trading extends beyond the Kyoto Protocol and appears well-established in both the public and the private sectors.

\section{Carbon Offsets}

Another market-based mitigation possibility for companies failing to meet their emission allowances is carbon offsets. Offset projects comprise a variety of carbon storage and carbon dioxide emission-reducing activities such as improved energy efficiency, disposal of animal waste and methane or, of special interest here, agro-forestry projects. Offsets cater to both the compliance market (i.e., those where reductions are required by law) and the voluntary reductions market. Examples of the former include the Joint Implementation (JI) projects and Clean Development Mechanisms (CDM), both of which are found in the Kyoto Protocol. JI projects are emission reduction and carbon storage projects occurring between developed nations, whereas CDMs are project agreements between developed and developing nations. By sponsoring a JI or CDM project, a nation can earn carbon credits to offset its own emissions.

In contrast to the compliance market, the voluntary market comprises private groups and individuals simply wanting to reduce their "carbon footprint." Not compelled by law, these groups and individuals purchase carbon credits from offset projects in order to promote a carbon-neutral lifestyle. Today, many activities, such as professional society meetings, advertise themselves as "carbon neutral" through their purchase of sufficient credits to offset the travelrelated carbon dioxide emissions of their attendees. Emitting carbon dioxide on one part of the planet and then planting trees or grasses to sequester that carbon on another part is seen by some as an effective way of reducing the greenhouse effect because of the global nature of the climate problem.
Since the late 1990s, many carbon offset projects have been initiated around the world in response to rapidly increasing market demand. ${ }^{5}$ However, there is concern that some of the projects are not properly monitored, thus raising questions regarding their validity. According to the Intergovernmental Panel of Climate Change (IPCC), offset projects would absorb at most only about $15 \%$ to $20 \%$ of the carbon from fossil fuel emissions. ${ }^{6}$ Thus, as stated at the beginning of this article, carbon offset projects are seen as an interim measure that could take the world to a more sound emissions management policy. ${ }^{6}$

The carbon storage potential of rangelands has not received as much study as that for agriculture and forestry. ${ }^{7}$ This lack of attention stems, no doubt, from the relatively low carbon storage capacity per unit area, the extreme heterogeneity of rangeland soils and the fact that significant gains in carbon storage capacity would likely require major changes in existing rangeland management. ${ }^{8}$ Estimating the potential gains in carbon storage on rangeland soils is complicated and the synthesis of multiple studies rarely provides unambiguous findings with respect to land management impacts on carbon storage. However, with respect to two common range management activities, grazing generally causes total biomass and carbon to decline on rangelands, while vegetation burning over the long-term results in little change in carbon although the above- vs. below-ground allocations may be altered. ${ }^{9}$

\section{Semi-Arid Rangelands Study}

A recent study has examined the cost of sequestering carbon on semi-arid rangelands. ${ }^{10}$ The study assumed, purely hypothetically, that the State of Arizona contemplated selling credits for carbon offset projects on their state trust lands. The underlying notion was that reduced cattle grazing on state rangelands would increase soil carbon. This idea was tested by simulating range management conditions for 12 different USDA State Soil Geographic Database (STATSGO) soil profiles located near the Santa Rita Experimental Range and the Appleton-Whittell Research Ranch (Fig. 2), both in southern Arizona. The simulation results were applied spatially across a STATSGO soil polygon and the resulting total soil organic carbon stocks were calculated.

Metric-English Equivalent Measures

\begin{tabular}{|l|l|}
\hline Metric unit & Equivalent English units \\
\hline 1 metric ton & 2204.622 pounds \\
\hline 1 hectare & 2.471 acres \\
\hline
\end{tabular}

For each soil profile, a "business-as-usual" scenario where cattle were allowed to graze was simulated and compared to a situation where the cattle were hypothetically removed from the land. The business-as-usual scenario was rotational grazing with an average of 0.46 animal unit 


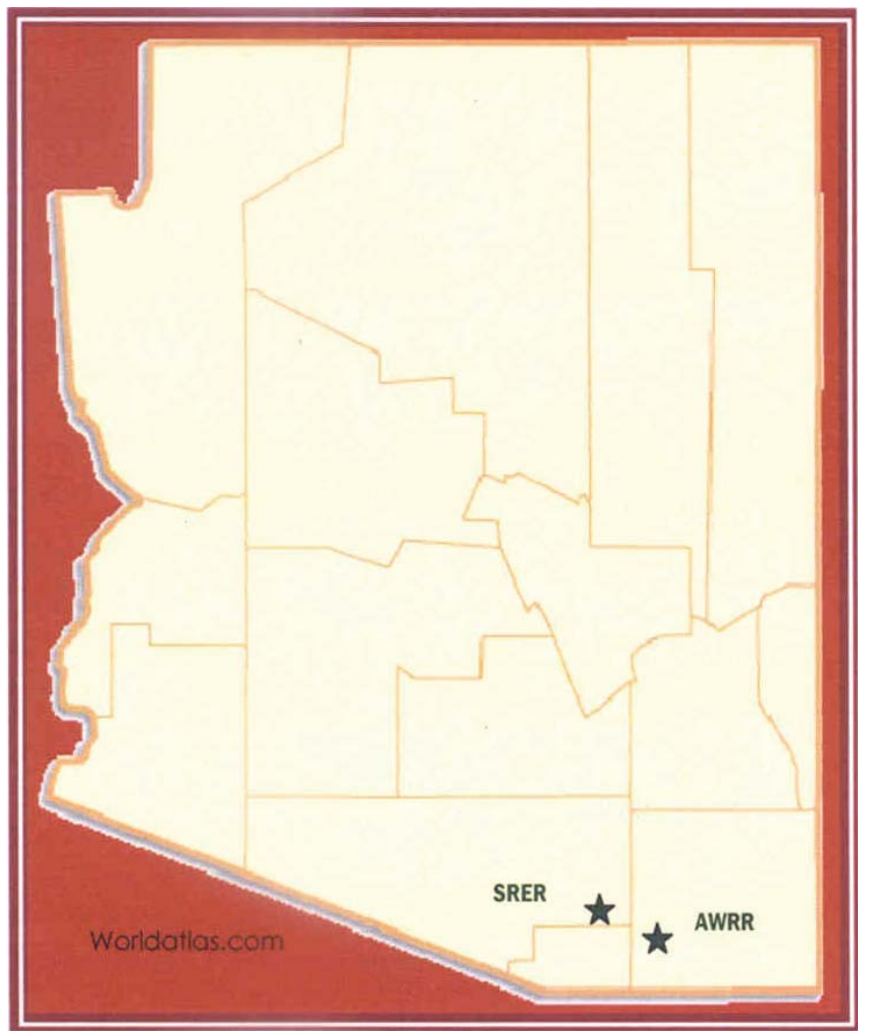

Figure 2. Soil carbon accumulations due to grazing removals were simulated for 12 STATSGO soil profiles located near the Santa Rita Experimental Range (SRER) and the Appleton-Whittell Research Ranch (AWRR) in southern Arizona.

months (AUMs) per hectare per year. The net storage of metric tons of carbon per hectare for a 25-year period was simulated for each soil profile using EPIC (Environmental Policy Integrated Climate), a process-based daily time-step model of agroecosystems. ${ }^{11}$ EPIC was calibrated with research data from sites such as one located on the Santa Rita Experimental Range (Fig. 3).

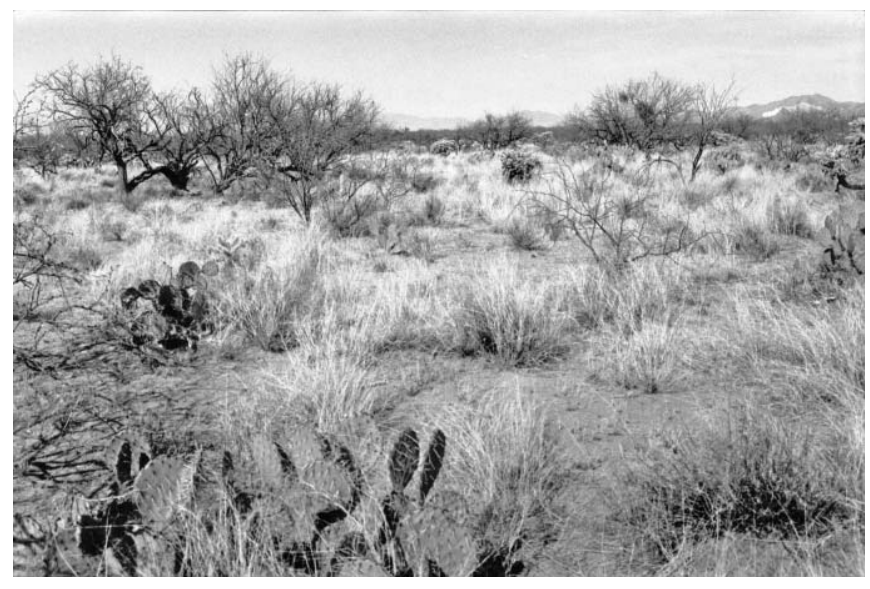

Figure 3. Site in the Santa Rita Experimental Range near Rincon Peak, Arizona, used to calibrate the EPIC model. Vegetation includes Lehmann lovegrass, cholla, prickly pear cactus, burroweed, mesquite. Photo by M. McClaran.
The accounting perspective was derived from the New Mexico-Arizona Enabling Act of 20 June 1910, which requires that the State obtain the highest financial returns possible from their trust lands. The cost of sequestrating the carbon was taken as the opportunity cost of lost state grazing revenues due to the reduction of AUMs discounted over the 25 years; to this were added soil carbon monitoring costs. Arizona state land grazing fees, in recent years, have ranged from $\$ 1.95$ to $\$ 2.52$ per AUM. ${ }^{12}$ Eleven years of state grazing fees (i.e., 1996-2006), stated in constant 2002 dollars, were averaged and multiplied by 0.46 to reflect the dollar amount lost annually per hectare due to cattle removal. This value was then projected, based upon historical trends, to increase at $1 \%$ real per year over the 25 -year period. The estimated costs for monitoring the soil carbon accumulation were estimated at $5 \%$ of the grazing fees. These total annual costs were then discounted by $4 \%$ real over the 25-year period and summed to obtain the present value per hectare opportunity cost of grazing reduction and carbon monitoring. The study did not take into account tax revenue lost by the state due to reduction in cattle sales, the lost property taxes from defunct ranches, compensation to ranch owner for their loss of improvements made on state trust land, or loss of revenue to local businesses that sell to cattle ranchers because these costs do not directly impact state trust land revenues.

The calculated carbon sequestration costs were then compared to actual carbon dioxide offset trading prices to determine if semi-arid rangelands might be competitive participants in those markets. This comparison required atomic weight conversions ${ }^{13}$ because the Arizona study, like most terrestrial studies, calculated the cost of sequestering per metric ton of carbon whereas the trading prices are per metric ton of carbon dioxide equivalent. The conversion formula was as follows: $\mathrm{P}_{\mathrm{CO} 2 \mathrm{e}}=0.2727 \times \mathrm{P}_{\mathrm{C}}$; where $\mathrm{P}_{\mathrm{CO} 2 \mathrm{e}}=$ price per metric ton carbon dioxide equivalent, $0.2727=$ price conversion factor based upon the ratio of atomic weights of carbon (12) and carbon dioxide (44), and $\mathrm{P}_{\mathrm{C}}=$ price per metric ton of carbon.

With regard to the study's results, the 25-year EPICsimulations (Table 1) indicted that all but one of the soil profiles (AZ 272) yielded an increase in carbon accumulation when the land was switched from rotational grazing to no grazing. Likewise, the discounted costs per metric ton of carbon sequestration for all soil profiles were positive with the exception of those for profile AZ 272 (Table 1). The key question, however, is just how well do these estimated carbon sequestration costs, when converted to carbon dioxide equivalent values (Table 1 , column 3), compare to actual carbon offset trading prices (Table 2)? In most instances the semiarid rangeland sequestration costs are less than, hence competitive with, current trading prices. For example, the sequestration costs for soil profiles AZ007, AZ038, AZ054, AZ060, AZ066, AZ146, and AZ251 are all less than the going prices paid by any listed trader. Even 
Table 1. Simulated soil carbon accumulation in metric tons per hectare for 12 soil types over 25 years due to grazing reduction, cost per ton of the accumulated carbon, and cost per ton of the carbon dioxide equivalent

\begin{tabular}{|c|c|c|c|}
\hline $\begin{array}{c}\text { Soil } \\
\text { type }\end{array}$ & $\begin{array}{c}\text { Simulated soil } \\
\text { carbon } \\
\text { accumulation }\end{array}$ & $\begin{array}{c}\text { Soil } \\
\text { carbon } \\
\text { cost } \\
\text { per ton }\end{array}$ & $\begin{array}{c}\mathbf{C O}_{2} \\
\text { equivalent } \\
\text { cost } \\
\text { per ton }\end{array}$ \\
\hline AZ007 & 1.958 & $\$ 9.98$ & $\$ 2.72$ \\
\hline AZ016 & 1.419 & 13.78 & 3.76 \\
\hline AZ021 & 0.374 & 52.27 & 14.25 \\
\hline AZ038 & 2.271 & 8.61 & 2.35 \\
\hline AZ050 & 0.277 & 70.57 & 19.24 \\
\hline AZ054 & 3.874 & 5.05 & 1.38 \\
\hline AZ060 & 3.777 & 5.18 & 1.41 \\
\hline AZ066 & 3.547 & 5.51 & 1.50 \\
\hline AZ146 & 2.509 & 7.79 & 2.12 \\
\hline AZ246 & 0.143 & 136.70 & 37.28 \\
\hline AZ251 & 2.459 & 7.95 & 2.17 \\
\hline AZ272 & -0.138 & $\mathrm{NA}$ & $\mathrm{NA}$ \\
\hline
\end{tabular}

Table 2. Survey of some recent carbon offset trading prices (dollars per metric ton of $\mathrm{CO}_{2}$ )

\begin{tabular}{|l|c|}
\hline Offset Trader, Location & Offset price \\
\hline Chicago Climate Exchange, US & 3.00 \\
\hline AtmosClear Climate Club, US & 3.56 \\
\hline Carbonfund.org, US & 4.30 \\
\hline e-Blue Horizons, US & 5.00 \\
\hline DriveNeutral.org, US & 6.93 \\
\hline DrivingGreen, Ireland & 8.00 \\
\hline Terrapass, US & 8.26 \\
\hline Native Energy, US & 13.20 \\
\hline The CarbonNeutral Company, UK & 14.00 \\
\hline Cleaner Climate, UK \& Australia & 15.00 \\
\hline Sustainable Travel International, US & 15.25 \\
\hline Climate Friendly, Australia & 16.00 \\
\hline Uncook the Planet, Australia & 19.45 \\
\hline Bonneville Environmental Foundation, & 29.00 \\
\hline US & 33.00 \\
\hline Myclimate, Switzerland & \\
\hline Adapted from: http://www.ecobusinesslinks.com \\
\hline
\end{tabular}

the higher carbon dioxide equivalent sequestration costs (Table 1, column 3) such as for AZ021 and AZ050 are less than several of the offset trader offerings. Indeed, only the price for AZ246 at $\$ 37.28$ per metric ton exceeded the entire array of trader buying prices.

\section{Conclusions}

The potential of rangelands for trading in carbon-offset markets is a function of both the land's rate of carbon accumulation and its cost as determined, in part, by competing uses such as grazing fees. Although semiarid rangelands may accumulate carbon at low rates relative to forests and agricultural lands, the cost of carbon sequestration on semiarid rangelands is also sometimes quite low. For example, in this study Arizona State Lands opportunity cost represented by uncollected grazing fees was about $\$ 2.00$ per AUM. By comparison, USDA Forest Service and Bureau of Land Management grazing fees are even less at about $\$ 1.56$ per AUM, while other state land grazing fees are as low as $\$ 1.35$ per AUM. ${ }^{14}$ To be sure, however, it is possible that costs other than grazing fees could be higher than those used in this study. For example, higher soil carbon monitoring costs and fencing to exclude cattle from nongrazed areas could contribute significantly to sequestration costs. Furthermore, the dedication of semiarid rangelands to carbon sequestration at the expense of cattle grazing raises some potentially potent equity issues that are best dealt with through the political system. Future scrutiny of the rapidly changing carbon market is, nevertheless, warranted to determine if managing for offsets is a worthwhile endeavor. Some semiarid rangeland soils may be candidates for carbon offsets management and could provide attractive new economic opportunities for rangeland managers.

\section{References}

1. Follett, R. F., J. M. Kimble, and R. Lal [eds.]. 2001. The potential of U.S. grazing lands to sequester carbon and mitigate the greenhouse effect. Boca Raton, FL, USA: Lewis Publishers. $442 \mathrm{p}$.

2. Campbell, S., S. Mooney, J. P. Hewlett, D. J. Menkhaus, And G. F. VAnce. 2004. Can ranchers slow climate change? Rangelands 26(4):16-22.

3. Tietenberg, T. 2002. The tradable permits approach to protecting the commons: what have we learned? In: E. Ostrom, T. Dietz, N. Dolsak, P. C. Stern, S. Stonich, and E. U. Weber [EDs.]. The drama of the commons. Washington, DC, USA: The National Academies Press. p. 197-232.

4. Labatt, S., and R. R. White. 2007. Carbon finance: the financial implications of climatic change. Hoboken, NJ, USA: John Wiley \& Sons. p. 137-166.

5. Labatt, S., And R. R. White. 2007. Carbon finance: the financial implications of climatic change. Hoboken, NJ, USA: John Wiley \& Sons. p. 164.

6. Labatt, S., and R. R. White. 2007. Carbon finance: the financial implications of climatic change. Hoboken, NJ, USA: John Wiley \& Sons. p. 52. 
7. Schnable, R. R., A. J. Franzluebbers, W. L. Stout, M. A. Sanderson, and J. A. Stuedemann. 2001. Chapter 12, The effects of pasture management practices. In: R. F. Follett, J. M. Kimble, and R. Lal [EDs.]. The potential of U.S. grazing lands to sequester carbon and mitigate the greenhouse effect. Boca Raton, FL, USA: Lewis Publishers. p. 291-322.

8. Sobecki, T. M., D. L. Moffitt, J. Stone, C. D. Franks, and A. G. Mendenhall. 2001. Chapter 2, The broad-scale perspective on the extent, distribution, and characteristics of U.S. grazing lands. In: R. F. Follett, J. M. Kimble, and R. Lal [EDs.]. The potential of U.S. grazing lands to sequester carbon and mitigate the greenhouse effect. Boca Raton, FL, USA: Lewis Publishers. p. 21-63.

9. Rice, C. W., and C. E. Owensby. 2001. Chapter 13, The effects of fire and grazing on soil carbon in rangelands. In: R. F. Follett, J. M. Kimble, and R. Lal [EDs.]. The potential of U.S. grazing lands to sequester carbon and mitigate the greenhouse effect. Boca Raton, FL, USA: Lewis Publishers. p. 323-342.

10. Hutchinson, C. F., S. E. Marsh, M. Karpiscak, S. Mclaughlin, S. Drake, M. McClaran, J. E. DeSteiguer, R. C. Izaurralde, N. J. Rosenberg, A. Thomson, S. Liang, And E. Trobia. 2005. Establishing a basis for carbon management policy at the state level: carbon dynamics at site, landscape, and regional scales for Arizona State Lands. Final Report, NASA Research Grant NAG13-02004. Washington, DC, USA: Office of Earth Science, National Aeronautics and Space Administration.

11. Izaurralde, R. C., J. R. Williams, W. B. McGill, N. J. Rosenberg, and M. C. Quiroga Jakas. 2006. Simulating soil $\mathrm{C}$ dynamics with EPIC: model description and testing against long-term data. Ecological Modelling 192(3-4):362-384.

12. Arizona State Land Department, Natural Resources Division. Grazing lease program. Available at: http://www. land.state.az.us/programs/natural/grazing_lease_admin/ grazing_fees.htm. Accessed 27 July 2007.

13. US Environmental Protection Agency. Conversion units. Available at: http://www.epa.gov/nonco2/units.html. Accessed 3 August 2007.

14. Vincent, C. H. 2006. Grazing fees: an overview and current issues. Congressional Research Service, Report for Congress, RS21232, 10 May 2006. 6 p.

Author is Professor, School of Natural Resources, University of Arizona,Tucson, AZ 85721-0043,USA, jedes@ag.arizona. edu. Preparation of this publication was supported in part by the Renerwable Resources Extension Act. 